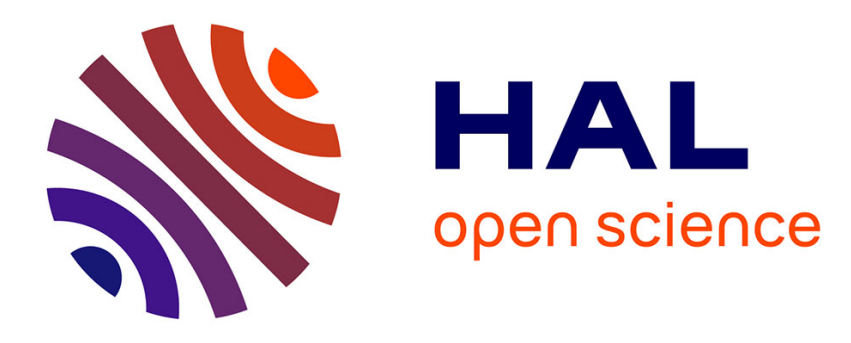

\title{
Multiple climbing fibers signal to molecular layer interneurons exclusively via glutamate spillover
}

German Szapiro, Boris Barbour

\section{To cite this version:}

German Szapiro, Boris Barbour. Multiple climbing fibers signal to molecular layer interneurons exclusively via glutamate spillover. Nature Neuroscience, 2007, 10 (6), pp.735-742. 10.1038/nn1907 . hal-02414890

\author{
HAL Id: hal-02414890 \\ https://hal.science/hal-02414890
}

Submitted on 16 Dec 2019

HAL is a multi-disciplinary open access archive for the deposit and dissemination of scientific research documents, whether they are published or not. The documents may come from teaching and research institutions in France or abroad, or from public or private research centers.
L'archive ouverte pluridisciplinaire HAL, est destinée au dépôt et à la diffusion de documents scientifiques de niveau recherche, publiés ou non, émanant des établissements d'enseignement et de recherche français ou étrangers, des laboratoires publics ou privés. 


\title{
Multiple climbing fibres signal to cerebellar molecular layer interneurones exclusively via glutamate spillover
}

\author{
Germán Szapiro and Boris Barbour \\ Laboratoire de Neurobiologie, Ecole Normale Supérieure, CNRS, \\ 46 rue d'Ulm, 75005 Paris, France.
}

April 5, 2007 


\begin{abstract}
Spillover of glutamate under physiological conditions has only been established as an adjunct to conventional synaptic transmission. Here we describe a pure spillover connection. It is between the climbing fibre and molecular layer interneurones in the cerebellar cortex. We show that instead of acting via conventional synapses, multiple climbing fibres activate AMPA and NMDA-type glutamate receptors on interneurones exclusively via spillover. Spillover from the climbing fibre represents a form of glutamatergic volume transmission that could be triggered in a regionalised manner by experimentally-observed synchronous climbing fibre activity. Climbing fibres are known to direct parallel fibre synaptic plasticity in interneurones, so one role of this spillover is likely to be in controlling synaptic plasticity.
\end{abstract}

\title{
Introduction
}

Spillover of neurotransmitter - action at synaptic contacts other than those where it was released - has proved to be a controversial subject. For simple small glutamatergic synapses, spillover at physiologically-plausible activity levels has only rarely been reported (Arnth-Jensen et al., 2002) and modelling suggests that spillover of glutamate at simple synapses is probably not significant (Barbour, 2001) (but cf Rusakov and Kullmann, 1998). It has been argued that spillover would reduce synaptic independence and hence reduce the storage capacity of the brain (Barbour, 2001). However, the effect of spillover would not be disadvantageous at all synapses. In contrast to the many small synapses at which spillover is probably unimportant, there exist in the brain a number of specialised synapses where spillover has been clearly demonstrated and where its functional role is apparent. These include the avian Calyx of Held synapse (Trussell et al., 1993) and the cerebellar mossy fibre-granule cell synapse (DiGregorio et al., 2002; Nielsen et al., 2004). However, these connections also mediate conventional synaptic transmission and the role of spillover is essentially one of amplification-increasing the post- 
synaptic response to a given amount of transmitter. Physiological actions of spillover glutamate in the absence of conventional synaptic transmission have so far been restricted to glial cells (Clark and Barbour, 1997; Bergles and Jahr, 1997).

Cerebellar climbing fibres constitute one of the two major afferent pathways to the cerebellum. They play a unique role in supervising motor learning in the cerebellum, notably at the parallel fibre-Purkinje cell synapse in the cerebellar cortex. Beyond the well-characterised input to Purkinje cells, climbing fibres have been demonstrated to signal to glial cells via synaptic transmission (Lin et al., 2005), perisynaptic transmission (Clark and Barbour, 1997; Bergles and Jahr, 1997), and ectopic release (Matsui and Jahr, 2003). Scattered anatomical studies have also mentioned the possibility of a climbing fibre-molecular layer interneurone synapse (e.g. Palay and ChanPalay, 1974; Sugihara et al., 1999).

Recently, Jörntell and Ekerot (Ekerot and Jörntell, 2001; Jörntell and Ekerot, 2002, 2003) identified a climbing fibre input to molecular layer interneurones (stellate and basket cells) and showed that it directed parallel fibre plasticity in these cells. However, the underlying synaptic mechanisms were not characterised beyond the initial current-clamp recordings. A surprising twist in the study of this connection is the very recent demonstration that it is a prime example of a novel type of axo-dendritic (or axo-somatic) contact (Kollo et al., 2006). Despite extensive and tight apposition between axonal (climbing fibre) and somatodendritic (interneurone) membranes, the apparent absence of vesicles and glutamate receptors argues against classical synaptic transmission occurring at these junctions.

In this paper, we confirm the existence of the climbing fibre-interneurone connection and characterise its mechanism of transmission. We shall show that it is mediated exclusively by spillover of glutamate and that multiple climbing fibres can influence a single interneurone. This spillover provides a mechanism allowing climbing fibres to signal to numerous synapses in a defined spatial region by a form of glutamatergic volume transmission. 


\section{Methods}

Animal experimentation methods complied with French, European and NIH guidelines. Young male Wistar rats (P17-P25) were killed by decapitation and the cerebellum rapidly dissected into a cold low-sodium saline containing (in mM): sucrose 230; $\mathrm{NaHCO}_{3} 26, \mathrm{KCl} 3 ; \mathrm{NaH}_{2} \mathrm{PO}_{4} 1.25, \mathrm{CaCl}_{2}$ 0.8; $\mathrm{MgCl}_{2} 8$; D-glucose 25; bubbled with $95 \% \mathrm{CO}_{2} / 5 \% \mathrm{O}_{2}$, supplemented with $50 \mu \mathrm{M}$ D-APV. Sagittal and transverse slices $360 \mu \mathrm{m}$ thick were cut in the same solution, using a Microm HM650V slicer. Slices recovered for $60 \mathrm{~min}$ in standard extracellular saline at $33^{\circ} \mathrm{C}$, containing (in $\mathrm{mM}$ ): $\mathrm{NaCl}$ 125; $\mathrm{NaHCO}_{3} 26, \mathrm{KCl} 3 ; \mathrm{NaH}_{2} \mathrm{PO}_{4} 1.25, \mathrm{CaCl}_{2} 2 ; \mathrm{MgCl}_{2} 1 ;$ D-glucose 25; bubbled with $95 \% \mathrm{CO}_{2} / 5 \% \mathrm{O}_{2}$. Thereafter, the slices were stored at room temperature.

Whole-cell voltage-clamp and current-clamp recordings were obtained at $30-33^{\circ} \mathrm{C}$ from molecular layer interneurones using a Cairn Optopatch. Cells were usually clamped to $-66 \mathrm{mV}$. One of two internal solutions was used: a K-gluconate-based internal or a Cs/TEA-methanesulphonate-based internal. The compositions of these solutions were as follows. K-gluconate internal (in $\mathrm{mM}$ ): K-gluconate 130; $\mathrm{KCl} 10$; HEPES 10; $\mathrm{MgCl}_{2} 1$; sucrose 16; BAPTA 5; $\mathrm{Na}_{2}$ ATP 4; NaGTP 1; titrated to $\mathrm{pH} 7.3$ with KOH. Csmethanesulphonate internal (in $\mathrm{mM}$ ): $\mathrm{CsCH}_{3} \mathrm{O}_{3} \mathrm{~S}$ 135; TEA-Cl 5; HEPES 10; $\mathrm{MgCl}_{2}$ 1; sucrose 16; BAPTA 5; $\mathrm{Na}_{2}$ ATP 4; NaGTP; QX-314 10; titrated to $\mathrm{pH} 7.3$ with $\mathrm{CsOH}$. Voltages have been corrected for the junction potentials by $-8 \mathrm{mV}$ and $-6 \mathrm{mV}$, respectively (measured at $32^{\circ} \mathrm{C}$ ). The external solution contained $10 \mu \mathrm{M}$ bicuculline methochloride and muscimol $(4-5 \mu \mathrm{M})$ : the combination occluded GABAergic synaptic currents but also induced a small tonic inhibitory conductance that reduced activity in coupled interneurones, which would otherwise have interfered with the recordings. Cyclothiazide was diluted from a $100 \mathrm{mM}$ stock in DMSO. Chemicals and drugs were obtained from Sigma and Tocris. An isolated stimulator was connected to a saline-filled patch electrode; stimulation frequency for recording was $0.1 \mathrm{~Hz}$.

Data were acquired using PClamp software (Molecular Dynamics) and analysed within the Igor (Wavemetrics) graphical analysis environment. 
Where responses were fitted by exponentials, both rising and decay phases were fitted simultaneously. The onset phase was always represented by a single exponential, while the decay phase was fitted with one or two components. The sum of the exponential amplitudes was constrained to be zero at the time of response onset (also fitted), in order to ensure return to the baseline.

Unless otherwise stated, means and standard deviations are given in the text and significance was tested using the non-parametric Wilcoxon signed rank test (two-tailed). Some statistical analysis was performed using GNU R. In particular, the statistical test for comparing two Poisson rates follows the description given in Chapter 9 of Cox and Lewis (1966). This requires summation of a binomial distribution, for which the exact binomial test (binom.test) in GNU R was used.

\section{Results}

\section{Climbing fibres make strongly-depressing connections on in- terneurones}

We made patch-clamp recordings from molecular layer interneurones (most of whose somata were near the Purkinje cell layer) in cerebellar slices. It was trivial to elicit rapid EPSCs that facilitated-representing granule cell inputs (Fig. 1a) (Xu-Friedman and Regehr, 2000). The mean amplitude of the inputs we recorded was $249 \pm 273 \mathrm{pA}(n=20$; these are potentially compound responses). The $20-80 \%$ rise-time was $0.41 \pm 0.14 \mathrm{~ms}$ and the decay time constant $1.85 \pm 0.52 \mathrm{~ms}$. (The extent and timecourse of the facilitation is quantified below.) More rarely, however, we were able to isolate inputs of a strikingly different nature, which displayed marked paired-pulse depression (Fig. 1b). We considered these as putative climbing fibre inputs, since climbing fibre inputs to other cells depress similarly (Konnerth et al., 1990; Lin et al., 2005). They were all-or-none and had an average amplitude of $99 \pm 94 \mathrm{pA}(n=30), 20-80 \%$ rise-time of $0.78 \pm 0.27 \mathrm{~ms}$ and a decay time constant of $3.4 \pm 1.4 \mathrm{~ms}$. The rise-times and decay time constants were 
significantly different from those of the parallel fibre inputs $\left(P<10^{-7}\right.$ for both parameters). Another difference between the two classes of inputs was their variability. This was quantified by the coefficent of variation (standard deviation/mean: $0.43 \pm 0.23, n=12$, for PF inputs; $0.20 \pm 0.10, n=12$, for $\mathrm{CF}$ inputs; $\mathrm{P}=0.005$ ) and the Fano factor (variance/mean: $32.3 \pm 31.8 \mathrm{pA}$ for $\mathrm{PF}$ inputs; $3.9 \pm 2.7 \mathrm{pA}$ for $\mathrm{CF}$ inputs; $\mathrm{P}<10^{-5}$ ). If both inputs were composed of the sum of identical independent random variates (e.g., mEPSCs), but in different numbers (to explain the different amplitudes), they would still have the same Fano factor. Since climbing fibre inputs have a lower Fano factor than parallel fibre inputs, this indicates that they are not composed of the same 'building blocks' as the parallel fibre input (or conceivably that they are not independent).

The recordings here were carried out at $\sim 32^{\circ} \mathrm{C}$. In 4 cells we compared responses at 32 and $37^{\circ} \mathrm{C}$ to confirm that the climbing fibre response was present at physiological temperatures (data not shown). At $37^{\circ} \mathrm{C}$ the amplitude of the response was reduced by $26 \pm 11 \%$, the $20-80 \%$ rise-time was reduced by $16 \pm 15 \%$, but the decay was unaffected. The latency was $15 \pm$ $8 \%$ shorter.

The parallel fibre inputs recovered from facilitation with an average time constant of $116 \mathrm{~ms}$ (Fig. 1c), close to the values previously reported (XuFriedman and Regehr, 2000) and as observed in Purkinje cells (Konnerth et al., 1990). In contrast, the putative climbing fibre input showed a very slow recovery from depression $(\tau=2.1 \mathrm{~s}$; Fig. 1d), strongly reminiscent of climbing fibre inputs to Purkinje cells (Konnerth et al., 1990) and NG2 ${ }^{+}$-glia (Lin et al., 2005).

We further strengthened the identification of the climbing fibre input by stimulating in the molecular layer at distances $>600 \mu \mathrm{m}$ from the interneurone, sometimes in neighbouring folia, i.e., transfolial stimulation. In sagittal slices, the only excitatory fibre whose branches show significant extent in the sagittal plane and also reach the molecular layer is the climbing fibre. At such distances, we were able to elicit apparently identical depressing responses (Fig. 1e), and only such responses $(n=4)$. These presumably reflect the initiation of an action potential in one terminal branch of the 
climbing fibre, antidromic propagation to a branch point, and then orthodromic propagation in the branch contacting the recorded cell.

Fig. 1f shows typical current-clamp responses for the two types of input. The parallel fibre input was elicited by juxta-threshold stimulation in the granule cell layer. The interneurone was maintained near $-74 \mathrm{mV}$. The kinetic properties of EPSPs of the two inputs were as follows. Parallel fibre $(n=$ 5): mean amplitude $1.4 \pm 1.2 \mathrm{mV}, 20-80 \%$ rise-time $0.66 \pm 0.20 \mathrm{~ms}$, decay time constant $4.8 \pm 1.5 \mathrm{~ms}$. Climbing fibre $(n=5)$ : mean amplitude $5.5 \pm$ $2.5 \mathrm{mV}, 20-80 \%$ rise-time $1.2 \pm 0.4 \mathrm{~ms}$, decay time constant $6.9 \pm 4.1 \mathrm{~ms}$. The difference in rise-times ( $P=0.05$; two-tailed t-test) is consistent with the description of Jörntell and Ekerot (2003).

We obtained final proof that the climbing fibre was the source of these depressing responses by recording from Purkinje cells and interneurones simultaneously and stimulating a common climbing fibre input (Fig. 2a). The EPSCs in both cells displayed correlated all-or-none behaviour as the stimulation intensity was varied around the threshold by a small amount (Fig. 2b), proving the commonality of the input to the two cells. Interestingly, the interneurone response was significantly delayed compared to the Purkinje cell response (Fig. 2c). The mean difference of the time to $5 \%$ rise was $0.83 \pm$ $0.52 \mathrm{~ms}$ (interneurone succeeding the Purkinje cell; $P=0.02 ; n=7$ ). This is consistent with the description by Jörntell and Ekerot (2003), who highlighted such a delay between the climbing fibre EPSP in the interneurone and the preceding local field potential, which probably reflects the synaptic conductance in the Purkinje cell. The delay is likely to be due in part to conduction along the climbing fibre within the molecular layer.

\section{Climbing fibres activate NMDA as well as AMPA-type gluta- mate receptors}

We next characterised the postsynaptic receptors mediating the climbing fibre response. Under control conditions, the EPSC was blocked by $4 \mu \mathrm{M}$ NBQX (Fig. 3a), indicating that the EPSC was mediated by AMPA/kainate receptors. The mean kinetic parameters for this component were $(n=5)$ : 
amplitude $65 \pm 31 \mathrm{pA} ; 20-80 \%$ rise-time $0.73 \pm 0.11 \mathrm{~ms}$; decay time constant $3.11 \pm 0.69 \mathrm{~ms}$. The subsequent nominal removal of $\mathrm{Mg}$ from the solution (and addition of $45 \mu \mathrm{M}$ D-serine) always unmasked a slower component that was blocked by $50 \mu \mathrm{M}$ APV (Fig. 3a). The mean kinetic parameters of this component were $(n=5)$ : amplitude $9.1 \pm 8.3 \mathrm{pA} ; 20-80 \%$ rise-time 7.9 $\pm 3.6 \mathrm{~ms}$; decay time constant $98 \pm 86 \mathrm{~ms}$ (the decay time constant is approximate, since the paired-pulse protocol employed did not allow for full decay of the NMDA component). In separate recordings, we confirmed the presence of an NMDA-receptor-mediated outward current at $+54 \mathrm{mV}$ that was blocked by $50 \mu \mathrm{M}$ APV ( $n=4$; data not shown). We further analysed the nature of the AMPA/kainate component with GYKI 53655, which abolished the control response in $n=5$ cells, indicating that it was a pure AMPA response and was not mediated by kainate receptors (Fig. 3b). Thus climbing fibres activate NMDA receptors as well as AMPA-type glutamate receptors, in marked contrast to the parallel fibre input, which does not activate NMDA receptors under basal stimulation conditions (Clark and Cull-Candy, 2002)

We also investigated the voltage dependence of the climbing fibre response in interneurones (Fig. 3c and d). The EPSC peak current (AMPA component) displayed a linear dependence upon voltage and reversed at zero ( $n=3-7$ cells), consistent with a non-specific cation conductance such as found in ionotropic glutamate receptors. The reversal close to zero is comparable to that observed for parallel fibre synapses in these cells (Clark and Cull-Candy, 2002).

The response of the climbing fibre is significantly longer-lasting than that of parallel fibre inputs (see above). This could reflect either a geuninely longlasting synaptic conductance or a brief conductance in a cellular compartment subject to a strong filtering, such as the axon. In order to distinguish between these two possibilities, we probed the timecourse of the underlying conductance by applying voltage jumps during the synaptic response. The rationale is that only a synaptic conductance that is still active at the time of the jump will be affected by the change of driving force. A typical experiment is shown in Fig. 4, which demonstrates that a voltage jump rapidly 
changed the synaptic response, showing the the underlying synaptic conductance ws genuinely long-lasting, rather than the result of filtering. The speed of change can be characterised by a time constant (Fig. 4c) whose value was $1.1 \pm 0.2 \mathrm{~ms}(n=4)$. This appears consistent with a dendritic location, as the axon is expected to be very poorly clamped and thus introduce stronger filtering.

\section{Multiple climbing fibres contact a single interneurone}

In the adult, most Purkinje cells are contacted by a single climbing fibre input. However, this one-to-one relation has been reported not to extend to the climbing fibre connection made on $\mathrm{NG}^{+}$-glia (Lin et al., 2005). We investigated whether interneurones might receive input from multiple climbing fibres by searching for two inputs with different stimulating electrodes. It often proved possible to isolate two inputs of different amplitudes, both displaying paired-pulse depression. In $n=7 / 8$ cases, these inputs did not interact via paired-pulse depression (Fig. 5a and b). The cell in which crossed paired-pulse depression appeared to occur was eliminated from further analysis, because a common climbing fibre was probably excited by the two stimulating electrodes. When stimulated simultaneously, the remaining putative pairs of climbing fibre inputs all summed to compound responses that were clearly larger than the individual responses (Fig. 5c). This could not occur if the two stimulating electrodes were exciting the same fibre, so the result proves that at least two climbing fibres were signalling to each interneurone.

As is the case in Fig. 5c, the compound responses were on average slightly larger than the predicted sum of isolated responses ( $6.5 \pm 12 \%$ greater), but this difference was not significant $(P=0.6)$.

\section{Miniature EPSCs of the climbing fibre could not be detected}

We then investigated the mechanisms underlying the low variability of the climbing fibre resopnse. As most synaptic variability is thought to arise from variations in the numbers of transmitter quanta released, we sought to determine the quantal properties of the granule cell and climbing fibre 
connections to interneurones.

A sensitive method for detecting and measuring quantal events is to record asynchronous miniature EPSCs following stimulation in the presence of strontium ions, which are known to substitute for calcium ions in the release process, but to be less effective and to induce a longer-lasting release, enabling asynchronous mEPSCs to be resolved (Dodge et al., 1969; Xu-Friedman and Regehr, 1999). This manipulation has previously been successfully employed to resolve mEPSCs released by the climbing fibre onto other cell types (Silver et al., 1998; Matsui and Jahr, 2003; Foster and Regehr, 2004; Lin et al., 2005). We carried out this experiment upon parallel fibre and climbing fibre inputs. Fig. 6a shows responses to stimulation of what was probably a single granule cell input. Nominal removal of extracellular calcium ions and addition of $5 \mathrm{mM} \mathrm{Sr}$ caused a large reduction of the phasic response and the appearance of spontaneous mEPSCs in the period following the stimulation (i.e., tens of ms). Climbing fibre connections showed quite different behaviour from parallel fibres in strontium-no asynchronous mEPSCs were apparent (Fig. 6b).

In order to quantify the frequencies of mEPSC occurrence in the presence of $\mathrm{Sr}$ ions, it was necessary to take into account the fact that spontaneous (m)EPSCs, mostly arising at other synapses, are observed at a low rate in interneurones. We therefore compared the rates of EPSC detection within defined windows before $(-311 \rightarrow-16 \mathrm{~ms})$ and after $(14 \rightarrow 54 \mathrm{~ms})$ stimulation. EPSCs were detected and measured automatically (see Methods). The results of a typical analysis of a granule cell input are represented as cumulative frequency plots for pre- and post-stimulus periods in Fig. 6c. A clear excess of mEPSCs above the background rate is observed for the period following the stimulus. The detection of mEPSCs is limited by the recording noise, which gives rise to an increasing number of false positives as the detection threshold is lowered below about $10 \mathrm{pA}$. We therefore tested the significance of the different rates of mEPSC detection above a threshold amplitude of $10 \mathrm{pA}$, before and after stimulation, using the statistical test described in the methods (which enabled us to evaluate the significance individually for each connection). For each parallel fibre connection tested 
$(n=4)$, the rate of mEPSC detection after stimulation (mean $12.3 \pm 4.5 \mathrm{~Hz})$ was significantly greater than before (mean $2.1 \pm 1.4 \mathrm{~Hz} ; P<10^{-4}$ in all cases). The increased rate of mEPSC detection after the stimulus results from the action of $\mathrm{Sr}$ and does not reflect normal 'delayed release' (Atluri and Regehr, 1998), since the post-stimulus detection rate under control conditions $(2.3 \pm 0.8 \mathrm{~Hz} ; n=3)$ was similar to the pre-stimulus rate in the same conditions $(1.8 \pm 0.9 \mathrm{~Hz})$ and much lower than the post-stimulus detection rates in $\mathrm{Sr}$.

In marked contrast to the behaviour of the parallel fibre synapse in $\mathrm{Sr}$, for all climbing fibre connections, the mEPSC detection rates before and after stimulation were not significantly different $(n=8, P$ range $0.06-1)$; an example is shown in Fig. 6d.

We also carried out a similar experiment for the climbing fibre input in the presence of cyclothiazide $(\mathrm{CTZ}, 100 \mu \mathrm{M})$, to enhance mEPSCs potentially below the detection threshold. Although CTZ potentiated and prolonged the evoked climbing fibre response in $\mathrm{Sr}$, we were still unable to detect any excess of mEPSCs following climbing fibre stimulation ( $n=4$, 47-120 sweeps, $\mathrm{P}=0.07-0.83)$. In order to avoid detection bias caused by the longer decay phase of the evoked EPSC in the presence of CTZ and Sr (the bias could result from noise or the slope), detection was carried out in a time window $134 \rightarrow 274$ ms after stimulation. In all other climbing fibre connections studied in this way, mEPSCs were detected at these times (Silver et al., 1998; Matsui and Jahr, 2003; Foster and Regehr, 2004; Lin et al., 2005).

Thus, we could not detect mEPSCs of the climbing fibre to interneurone connection, suggesting that glutamate is not liberated directly opposite significant densities of receptors on the interneurone.

\section{Blocking glutamate uptake strongly potentiates the climbing fibre response}

We next performed experiments designed to test whether glutamate needed to diffuse a significant distance after its release to reach the interneurone. 
It is well-established both experimentally and theoretically that spillover responses are selectively reduced by the action of uptake (Barbour et al., 1994; Rusakov and Kullmann, 1998; Barbour, 2001; Brasnjo and Otis, 2001; Diamond, 2001; Arnth-Jensen et al., 2002; Marcaggi et al., 2003; Marcaggi and Attwell, 2005).

We therefore applied TBOA $(50 \mu \mathrm{M})$, a non-transported blocker of glutamate uptake, while recording parallel fibre and climbing responses. As expected, the effect on the parallel fibre response was minimal (Fig. 7a), with only a small slow component of the response being affected (this component may, moreover, reflect a spillover process: Barbour et al., 1994). Fitting the timecourse of the parallel fibre EPSC in TBOA sometimes required three exponential components (one for the onset and two for the decay). The fit parameter values in control conditions were A1 $=414 \pm 247 \mathrm{pA}, \mathrm{A} 2=-395$ $\pm 239 \mathrm{pA}, \mathrm{A} 3=-19 \pm 12 \mathrm{pA}, \tau_{1}=0.51 \pm 0.16 \mathrm{~ms}, \tau_{2}=1.40 \pm 0.37 \mathrm{~ms}$, $\tau_{3}=11.46 \pm 7.49 \mathrm{~ms}(n=4)$. In the presence of TBOA, these parameters were altered less than $10 \%$, except A3 $(2.41 \pm 2.66$ fold change; $P=0.37$; paired two-tailed Student's t-test) and $\tau_{3}(2.63 \pm 0.91$ fold change; $P=0.04$; paired two-tailed Student's t-test). The EPSC peak increased by $6 \pm 15 \%$ in TBOA ( $P=0.47$; paired two-tailed Student's t-test)

In marked contrast to the parallel fibre EPSC, the climbing fibre response was strongly enhanced and prolonged by TBOA (Fig. 7b). Its timecourse was satisfactorily fit by two exponentials, with control values of: amplitude $49 \pm 22 \mathrm{pA}$; onset time constant $1.2 \pm 0.7 \mathrm{~ms}$; decay time constant $4.2 \pm$ $0.8 \mathrm{~ms}(n=6)$. In TBOA, the amplitude was increased $2.6 \pm 2.19$ fold $(n=6, P=0.03)$ and both the onset time constant $(3.13 \pm 0.45$ fold increase; $P=0.03$ ) and the decay time constant (4.44 \pm 1.57 fold increase; $P=0.03)$ were also prolonged.

This sensitivity to uptake block suggests that glutamate from the climbing fibre does indeed diffuse over a significant distance before reaching the interneurone, allowing its concentration to be strongly reduced by uptake.

The effect of TBOA also rules out the possibility that the EPSC we record involves reversed glutamate uptake to release glutamate into the extracellular space or that forward glutamate uptake generates the EPSC in 
the interneurone, since both forward and backward glutamate uptake are blocked by TBOA (Marcaggi et al., 2005; Owe et al., 2006).

\section{Low-affinity AMPA-R antagonists strongly block the climbing fibre input}

The degree of inhibition of glutamate receptors by low-affinity competitive antagonists depends (at equilibrium) upon the competing concentration of glutamate, thus yielding information about the glutamate concentration underlying synaptic responses (Clements et al., 1992). If the climbing fibre response results from glutamate spillover, it would be expected to involve lower glutamate concentrations than standard synaptic transmission and therefore be particularly sensitive to block by such antagonists.

We applied the low-affinity antagonist of AMPA/kainate-type glutamate

receptors $\gamma$-D-glutamyl-glycine (DGG) at $0.375 \mathrm{mM}$ to parallel and climbing fibre inputs (Fig. 8). DGG blocked the parallel fibre inputs by $39 \pm 11 \%$ $(n=5)$, while it blocked the climbing fibre response by $72 \pm 7 \%(n=6)$. The difference was significant $(P=0.004)$ and thus suggests that during the climbing fibre response receptors are exposed to a lower concentration of glutamate than during the parallel fibre response.

The sensitivity to DGG of the climbing fibre response in interneurones further supports the notion that the EPSC is elicited by glutamate spillover.

\section{Discussion}

\section{Spillover nature of climbing fibre to interneurone transmission}

We have characterised the climbing fibre to molecular layer interneurone input. It displays strong and long-lasting paired-pulse depression and has both AMPA and NMDA receptor-dependent components. Multiple climbing fibres probably signal to each interneurone.

The climbing fibre connection to interneurones exhibits a number of unusual properties, in particular the absence of detectable mEPSCs, the invariance of response amplitudes, and the sensitivity to uptake block. These 
led us to consider three different mechanisms of synaptic signalling: standard transmission, ectopic release, and spillover.

The inability to detect mEPSCs suggests that transmitter release does not occur opposite any significant densities of glutamate receptors, thus arguing against both standard synaptic transmission and ectopic release. The absence of detectable mEPSCs is, however, consistent with a spillover mechanism, since the response could result from the interaction of many vesicles released from a large area of the climbing fibre, while individually each vesicle only produces a very attenuated response in the interneurone.

The strong potentiation by uptake blockers indicates that receptors are only reached after transmitter has diffused some distance. This again argues in favour of spillover and against both standard transmission and ectopic release.

Further support for the spillover mechanism is provided by the strong block of the climbing fibre-interneurone response by DGG - no other cerebellar synaptic response is as sensitive to this low-affinity antagonist, even at significantly higher DGG concentrations (Wadiche and Jahr, 2001; Foster and Regehr, 2004). The sensitivity to DGG that we observe also exceeds that recently reported for spillover responses observed in glutamate transporter knock-out mice (Takayasu et al., 2006). In those experiments, the spillover was detected in a Purkinje cell and thought to originate from a climbing fibre contacting a neighbouring Purkinje cell. $1 \mathrm{mM}$ DGG blocked the spillover responses by $70 \%$. Using a different low-affinity antagonist (kynurenate) at the cerebellar mossy fibre-granule cell synapse, DiGregorio et al. (2002) found a similar difference of block between direct synaptic and spillover responses to that observed here.

Finally, the recent electron microscopy of the climbing fibre-interneurone apposition (Kollo et al., 2006) argues strongly against both a standard synapse and ectopic release, because the authors were unable to detect significant densities of vesicles or glutamate receptors (either AMPA or NMDA types) at the junctions. Moreover, by demonstrating such close approach of the climbing fibre to the interneurone dendrite, the report also provides indirect support for the spillover hypothesis, since the action of spillover glu- 
tamate is strongest over short distances (Barbour, 2001). Unfortunately, our data provide no insight into the mysterious function of the potassium channel clusters found at the climbing fibre-interneurone appositions and it remains unclear whether there is any functional relation between the spillover signalling we demonstrate here and those clusters. Under our experimental conditions, the hyperpolarisation-depolaristion sequence required to disinactivate and activate $\mathrm{I}_{A}$-type potassium channels did not occur.

We conclude therefore that climbing fibre-interneurone signalling occurs via spillover, apparently in the absence of standard or ectopic synaptic responses in the interneurone. However, we have no way of determining the relative contributions of spillover from release onto Purkinje cells, NG2 ${ }^{+}$ cells and Bergmann glia (including ectopic release). Nevertheless, from the point of view of interneurone function, the precise source may not be important.

This is the first demonstration of a pure spillover ionotropic glutamate response under physiological conditions. Although it has been previously reported that depolarisation of mitral cells causes activation of NMDA receptors via spillover, those experiments employed long depolarisations to induce the glutamate release (Isaacson, 1999). In the cerebellum, parallel fibre responses attributed to spillover were only observed when using strong stimuli exciting compact bundles of parallel fibres (Barbour et al., 1994; Carter and Regehr, 2000; Marcaggi et al., 2003; Marcaggi and Attwell, 2005), an activity pattern that is unlikely to be physiological.

\section{Comparison with previous reports of climbing fibre-interneurone signalling}

Although we did not keep detailed records, we estimate that a climbing fibre connection could be found in a majority of the interneurones tested. We also estimate that multiple inputs are frequent. This fits with the report by Jörntell and Ekerot (2003) that all stellate and basket cells received climbing fibre inputs.

Our results agree closely with the observations made by Jörntell and 
Ekerot (2003) in their in vivo recordings identifying the climbing fibreinterneurone EPSP. They reported that climbing fibre EPSPs had a slower rise-time than parallel fibre EPSPs, consistent with the slower kinetics we observe for climbing fibre than parallel fibre responses. Jörntell and Ekerot (2003) also reported that the climbing fibre EPSP is delayed with respect to the local field potential thought to represent the climbing fibre synaptic conductance in the Purkinje cells, a property we confirm here.

The group of Konishi have reported that high-frequency $(5-50 \mathrm{~Hz})$ activation of climbing fibres causes a reduction of interneuronal inhibition recorded in Purkinje cells, via an action on AMPA receptors on the interneurone axon (Satake et al., 2000, 2004, 2006). The question arises of whether the EPSC reported here is linked to their effect. However, the properties reported by those authors show significant discrepancies with those we find. In particular, instead of high-frequency signalling to the axon, the EPSC we record appears to mediate low-frequency signalling (because of the strong paired-pulse depression) to AMPA receptors on the dendrites of the interneurone, as suggested by the voltage jumps in Fig. 4. Moreover, although there is evidence for the expression of functional NMDA receptors on interneurone axons (Glitsch and Marty, 1999; Duguid and Smart, 2004; Beierlein and Regehr, 2006), Clark and Cull-Candy (2002) have shown that only NMDA receptors on the dendrite are able to generate a current that is detectable from the soma. However, it remains possbile that any AMPA and NMDA receptors present on the interneurone axon might be activated by spillover from the climbing fibre.

An interesting question is whether the NMDA receptors activated by high-frequency parallel fibre stimulation (Carter and Regehr, 2000; Clark and Cull-Candy, 2002; Karakossian and Otis, 2004) are the same as those activated by the climbing fibre. If so, it will be interesting to evaluate which input provides the greater activation of these receptors under physiological conditions. 


\section{Physiological roles of the climbing fibre-interneurone connec- tion in network activity and synaptic plasticity}

The climbing fibre input to interneurones is excitatory. If several inputs from synchronous climbing fibres combine to excite individual interneurones strongly, synchronous activation of interneurones within a sagittal band might be expected, because this is the typical pattern of correlated climbing fibres (Lang et al., 1999). What would be the consequences of synchronous activation of interneurones? They inhibit most cells extending into the molecular layer, including, of course, the Purkinje cell. This inhibition would succeed the direct climbing fibre input to the Purkinje cell and may help truncate the complex spike. An intriguing idea is that this inhibition might also be responsible for the pause in Purkinje cell simple spike activity often observed after complex spikes (Granit and Phillips, 1956; Sato et al., 1992).

Jörntell and Ekerot $(2002,2003)$ have shown a very clear role for the climbing fibre in controlling parallel fibre to interneurone synaptic plasticity. When parallel fibres are stimulated alone at high frequency in vivo, no change of efficacy is observed. However, the same stimulation in conjunction with climbing fibre activity leads to a long-term potentiation. It seems unlikely that even multiple climbing fibre inputs would induce an electrical response that could be reliably distinguished from that of high-frequency parallel fibre activity. This raises the question of how the climbing fibre generates the clear signal that induces synaptic plasticity. The activation of NMDA receptors by the climbing fibre and subsequent calcium entry could represent an essentially non-electrical signal that might distinguish climbing and parallel fibre inputs, which have only been shown to activate NMDA receptors when stimulated in compact bundles, but not under basal stimulation conditions (Clark and Cull-Candy, 2002). Interestingly, NMDA receptor activation is necessary for (Smith and Otis, 2005) or can influence (Rancillac and Crepel, 2004) the induction of LTP in the interneurone (studied in vitro without the climbing fibre).

Beyond the input to interneurones that we demonstrate here, it seems 
plausible that spillover of glutamate may reach other cells in the molecular layer in a similar way - climbing fibre responses have been reported in Lugaro and Golgi cells, for instance (Ekerot and Jörntell, 2003), though it is not known whether they are also mediated by spillover. The climbing fibre may therefore provide a form of regionalised glutamatergic volume transmission reaching many cells with dendrites in the molecular layer. This signalling could subserve both developmental and physiological roles.

\section{Acknowledgements}

We thank Henrik Jörntell for help in identifying the climbing fibre input to interneurones. We thank David Colquhoun and Andrew Hawkes for indicating the test for comparing two Poisson rates to us. We are grateful to Christophe Mulle for the gift of GYKI 53655 and advice. We thank David Attwell, Tom Otis, and David DiGregorio for comments on the MS. We thank Clément Léna, Anne Feltz and many other members of the Laboratoire de Neurobiologie for helpful discussion and comments on the MS. We gratefully acknowledge the support of the ANR, Fondation Fyssen (fellowship to G.S.), CNRS, and ENS.

\section{References}

Arnth-Jensen, N., Jabaudon, D., and Scanziani, M. (2002). Cooperation between independent hippocampal synapses is controlled by glutamate uptake. Nat Neurosci, 5:325-31.

Atluri, P. P. and Regehr, W. G. (1998). Delayed release of neurotransmitter from cerebellar granule cells. J Neurosci, 18:8214-27.

Barbour, B. (2001). An evaluation of synapse independence. J Neurosci, 21:7969-7984.

Barbour, B., Keller, B. U., Llano, I., and Marty, A. (1994). Prolonged presence of glutamate during excitatory synaptic transmission to cerebellar Purkinje cells. Neuron, 12:1331-43. 
Beierlein, M. and Regehr, W. G. (2006). Local interneurons regulate synaptic strength by retrograde release of endocannabinoids. J Neurosci, 26:9935-43.

Bergles, D. E. and Jahr, C. E. (1997). Synaptic activation of glutamate transporters in hippocampal astrocytes. Neuron, 19:1297-308.

Brasnjo, G. and Otis, T. S. (2001). Neuronal glutamate transporters control activation of postsynaptic metabotropic glutamate receptors and influence cerebellar long-term depression. Neuron, 31:607-16.

Carter, A. G. and Regehr, W. G. (2000). Prolonged synaptic currents and glutamate spillover at the parallel fiber to stellate cell synapse. J Neurosci, 20:4423-34.

Clark, B. A. and Barbour, B. (1997). Currents evoked in Bergmann glial cells by parallel fibre stimulation in rat cerebellar slices. J Physiol, 502:335-50.

Clark, B. A. and Cull-Candy, S. G. (2002). Activity-dependent recruitment of extrasynaptic NMDA receptor activation at an AMPA receptor-only synapse. J Neurosci, 22:4428-36.

Clements, J. D., Lester, R. A., Tong, G., Jahr, C. E., and Westbrook, G. L. (1992). The time course of glutamate in the synaptic cleft. Science, 258:1498-501.

Cox, D. R. and Lewis, P. A. W. L. (1966). The statistical analysis of series of events. Chapman \& Hall.

Diamond, J. S. (2001). Neuronal glutamate transporters limit activation of NMDA receptors by neurotransmitter spillover on CA1 pyramidal cells. J Neurosci, 21:8328-38.

DiGregorio, D. A., Nusser, Z., and Silver, R. A. (2002). Spillover of glutamate onto synaptic AMPA receptors enhances fast transmission at a cerebellar synapse. Neuron, 35:521-33. 
Dodge, F. A., Miledi, R., and Rahamimoff, R. (1969). Strontium and quantal release of transmitter at the neuromuscular junction. J. Physiol. (Lond.), 200:267-83.

Duguid, I. C. and Smart, T. G. (2004). Retrograde activation of presynaptic NMDA receptors enhances GABA release at cerebellar interneuronPurkinje cell synapses. Nat Neurosci, 7:525-33.

Ekerot, C. and Jörntell, H. (2003). Synaptic input to cerebellar Lugaro and Golgi cells studied with whole cell recording in vivo. Abstract Viewer/Itinerary Planner. Washington, DC: Society for Neuroscience., page Program No. 274.3.

Ekerot, C. F. and Jörntell, H. (2001). Parallel fibre receptive fields of Purkinje cells and interneurons are climbing fibre-specific. Eur J Neurosci, 13:1303-10.

Foster, K. A. and Regehr, W. G. (2004). Variance-mean analysis in the presence of a rapid antagonist indicates vesicle depletion underlies depression at the climbing fiber synapse. Neuron, 43:119-31.

Glitsch, M. and Marty, A. (1999). Presynaptic effects of NMDA in cerebellar Purkinje cells and interneurons. J Neurosci, 19:511-9.

Granit, R. and Phillips, C. G. (1956). Excitatory and inhibitory processes acting upon individual Purkinje cells of the cerebellum in cats. J. Physiol. (Lond.), 133:520-547.

Isaacson, J. S. (1999). Glutamate spillover mediates excitatory transmission in the rat olfactory bulb. Neuron, 23:377-84.

Jörntell, H. and Ekerot, C. F. (2002). Reciprocal bidirectional plasticity of parallel fiber receptive fields in cerebellar Purkinje cells and their afferent interneurons. Neuron, 34:797-806.

Jörntell, H. and Ekerot, C. F. (2003). Receptive field plasticity profoundly alters the cutaneous parallel fiber synaptic input to cerebellar interneurons in vivo. $J$ Neurosci, 23:9620-31. 
Karakossian, M. H. and Otis, T. S. (2004). Excitation of cerebellar interneurons by group I metabotropic glutamate receptors. J Neurophysiol, 92:1558-65.

Kollo, M., Holderith, N. B., and Nusser, Z. (2006). Novel subcellular distribution pattern of A-type $\mathrm{K}+$ channels on neuronal surface. J Neurosci, 26:2684-91.

Konnerth, A., Llano, I., and Armstrong, C. M. (1990). Synaptic currents in cerebellar Purkinje cells. Proc Natl Acad Sci U S A, 87:2662-5.

Lang, E. J., Sugihara, I., Welsh, J. P., and Llinas, R. (1999). Patterns of spontaneous purkinje cell complex spike activity in the awake rat. $J$ Neurosci, 19:2728-39.

Lin, S. C., Huck, J. H., Roberts, J. D., Macklin, W. B., Somogyi, P., and Bergles, D. E. (2005). Climbing fiber innervation of NG2-expressing glia in the mammalian cerebellum. Neuron, 46:773-85.

Marcaggi, P. and Attwell, D. (2005). Endocannabinoid signaling depends on the spatial pattern of synapse activation. Nat. Neurosci., 8:776-81.

Marcaggi, P., Billups, D., and Attwell, D. (2003). The role of glial glutamate transporters in maintaining the independent operation of juvenile mouse cerebellar parallel fibre synapses. J. Physiol. (Lond.), 552:89-107.

Marcaggi, P., Hirji, N., and Attwell, D. (2005). Release of L-aspartate by reversal of glutamate transporters. Neuropharmacology., 49:843-9.

Matsui, K. and Jahr, C. E. (2003). Ectopic release of synaptic vesicles. Neuron, 40:1173-83.

Nielsen, T. A., DiGregorio, D. A., and Silver, R. A. (2004). Modulation of glutamate mobility reveals the mechanism underlying slow-rising AMPAR EPSCs and the diffusion coefficient in the synaptic cleft. Neuron, 42:75771. 
Owe, S. G., Marcaggi, P., and Attwell, D. (2006). The ionic stoichiometry of the GLAST glutamate transporter in salamander retinal glia. J Physiol, 577:591-599.

Palay, S. L. and Chan-Palay, V. (1974). Cerebellar cortex. Springer.

Rancillac, A. and Crepel, F. (2004). Synapses between parallel fibres and stellate cells express long-term changes in synaptic efficacy in rat cerebellum. J Physiol, 554:707-20.

Rusakov, D. A. and Kullmann, D. M. (1998). Extrasynaptic glutamate diffusion in the hippocampus: ultrastructural constraints, uptake, and receptor activation. J Neurosci, 18:3158-70.

Satake, S., Saitow, F., Rusakov, D., and Konishi, S. (2004). AMPA receptormediated presynaptic inhibition at cerebellar GABAergic synapses: a characterization of molecular mechanisms. Eur J Neurosci, 19:2464-74.

Satake, S., Saitow, F., Yamada, J., and Konishi, S. (2000). Synaptic activation of AMPA receptors inhibits GABA release from cerebellar interneurons. Nat Neurosci, 3:551-8.

Satake, S., Song, S. Y., Cao, Q., Satoh, H., Rusakov, D. A., Yanagawa, Y., Ling, E. A., Imoto, K., and Konishi, S. (2006). Characterization of AMPA receptors targeted by the climbing fiber transmitter mediating presynaptic inhibition of GABAergic transmission at cerebellar interneuron-Purkinje cell synapses. J Neurosci, 26:2278-89.

Sato, Y., Miura, A., Fushiki, H., and Kawasaki, T. (1992). Short-term modulation of cerebellar Purkinje cell activity after spontaneous climbing fiber input. J Neurophysiol, 68:2051-62.

Silver, R. A., Momiyama, A., and Cull-Candy, S. G. (1998). Locus of frequency-dependent depression identified with multiple-probability fluctuation analysis at rat climbing fibre-Purkinje cell synapses. J. Physiol. (Lond.), 510:881-902. 
Smith, S. L. and Otis, T. S. (2005). Pattern-dependent, simultaneous plasticity differentially transforms the input-output relationship of a feedforward circuit. Proc Natl Acad Sci U S A, 102:14901-6.

Sugihara, I., Wu, H., and Shinoda, Y. (1999). Morphology of single olivocerebellar axons labeled with biotinylated dextran amine in the rat. $J$ Comp Neurol, 414:131-48.

Takayasu, Y., Iino, M., Shimamoto, K., Tanaka, K., and Ozawa, S. (2006). Glial glutamate transporters maintain one-to-one relationship at the climbing fiber-Purkinje cell synapse by preventing glutamate spillover. J Neurosci, 26:6563-72.

Trussell, L. O., Zhang, S., and Raman, I. M. (1993). Desensitization of AMPA receptors upon multiquantal neurotransmitter release. Neuron, 10:1185-96.

Wadiche, J. I. and Jahr, C. E. (2001). Multivesicular release at climbing fiber-Purkinje cell synapses. Neuron, 32:301-13.

Xu-Friedman, M. A. and Regehr, W. G. (1999). Presynaptic strontium dynamics and synaptic transmission. Biophys. J., 76:2029-42.

Xu-Friedman, M. A. and Regehr, W. G. (2000). Probing fundamental aspects of synaptic transmission with strontium. J Neurosci, 20:4414-22. 

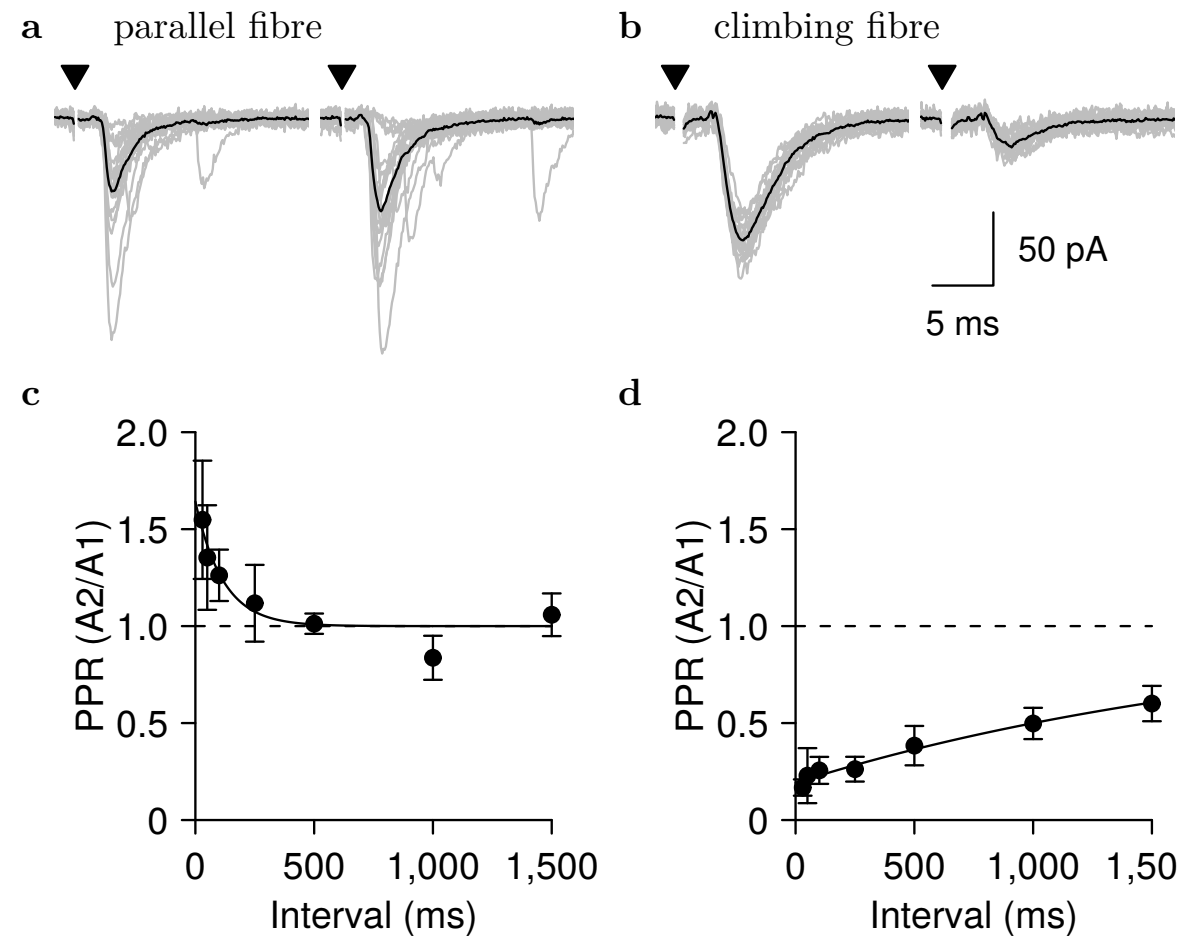

d

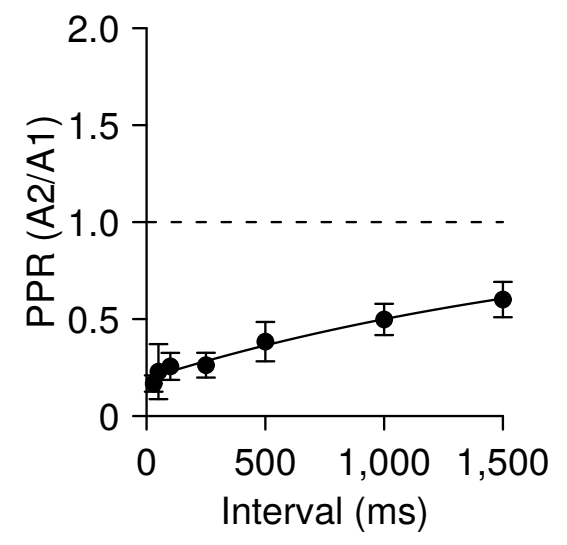

e transfolial

f granule cells climbing fibre
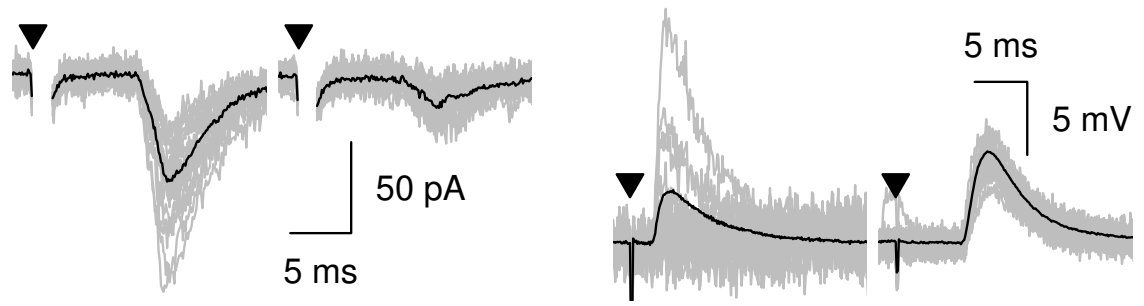

Figure 1: Putative climbing fibre responses display paired-pulse depression. a. A probable parallel fibre response displays paired-pulse facilitation (second amplitude/first amplitude, $\mathrm{A} 2 / \mathrm{A} 1=1.27$, interval $=$ $130 \mathrm{~ms}$ ). Individual sweeps (grey) and the average (black, $n=20$ ). In all figures, times of stimulation are marked by triangles and the stimulus artefacts have usually been blanked. b. A putative climbing fibre response displays marked paired-pulse depression $(\mathrm{A} 2 / \mathrm{A} 1=0.25$, interval $=130 \mathrm{~ms})$. Individual sweeps (grey) and the average (black, $n=20$ ). c. Recovery from paired-pulse facilitation for parallel fibre connections occurs with an average time constant of $116 \mathrm{~ms}$ and an intercept of 1.64 ( $n=7$ cells). d. Recovery from paired-pulse depression for putative climbing fibre inputs occurs with an average time constant of $2.1 \mathrm{~s}$ and an intercept of 0.19 ( $n=4-7$ cells). e. Transfolial stimulation: typical response recorded when stimulating in the distant molecular layer. Individual sweeps (grey) and the average (black, $n=$ 22). f. Voltage recordings: typical responses to juxta-threshold stimulation of granule cells (left; specimen traces in grey and the average of 100 in black) and a putative climbing fibre input in a different cell (right; specimen traces in grey and the average of 60 in black). 


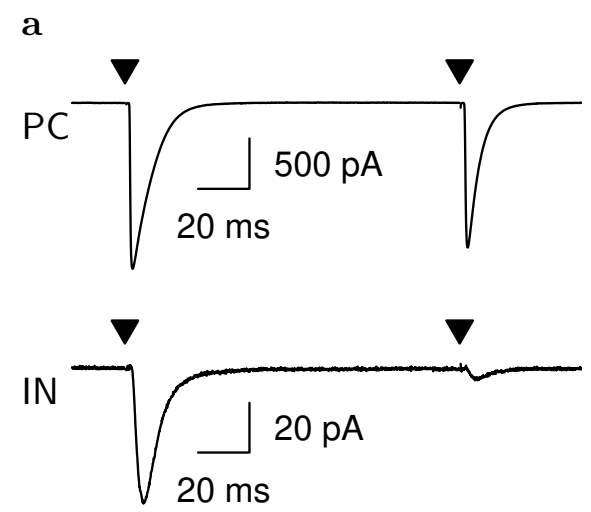

b

IN CF amplitude (pA)

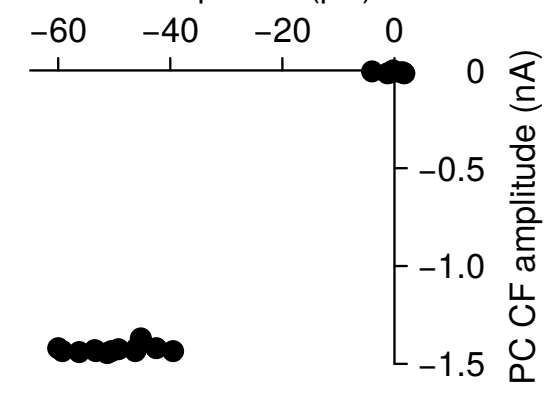

c

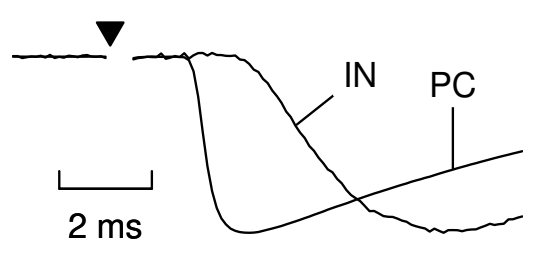

Figure 2: Purkinje cell and interneurone responses to common climbing fibre input display different latencies. a. Climbing fibre responses in simultaneously-recorded Purkinje cell (top) and interneurone (bottom); averages of 35 sweeps. Both cells were recorded with the Cs/TEAbased internal solution; the Purkinje cell was held at a depolarised potential to help inactivate voltage-dependent conductances. b. Scatter plot of peak responses in the Purkinje cell and interneurone measured as the stimulus intensity was varied by a small fraction around threshold. The perfect correlation shows that the responses were caused by a single common input. c. Same averages (first pulses) as in panel a but scaled to the same peak amplitude to facilitate comparison of their timecourses. The interneurone response has a markedly longer latency. 
a

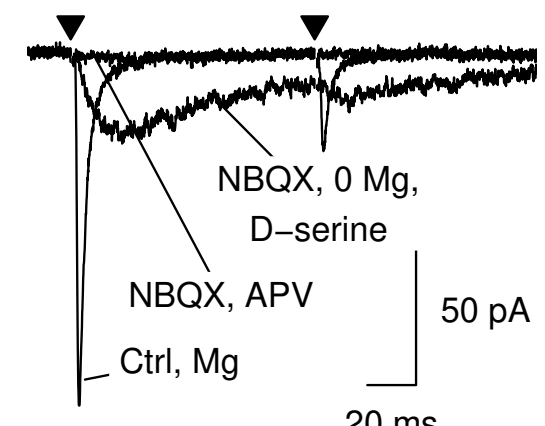

c

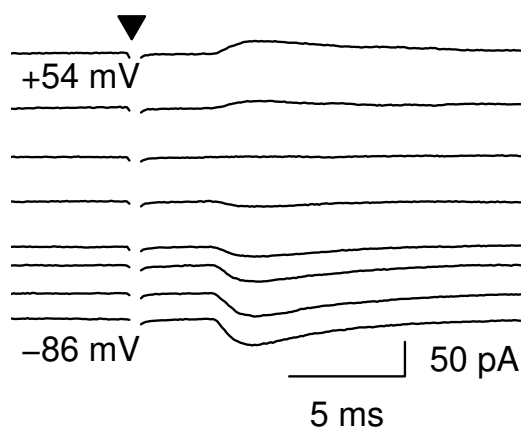

b

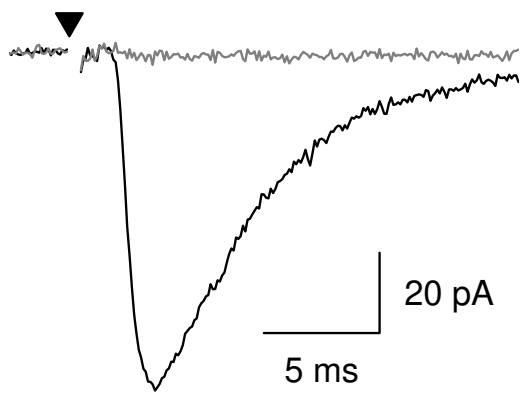

d

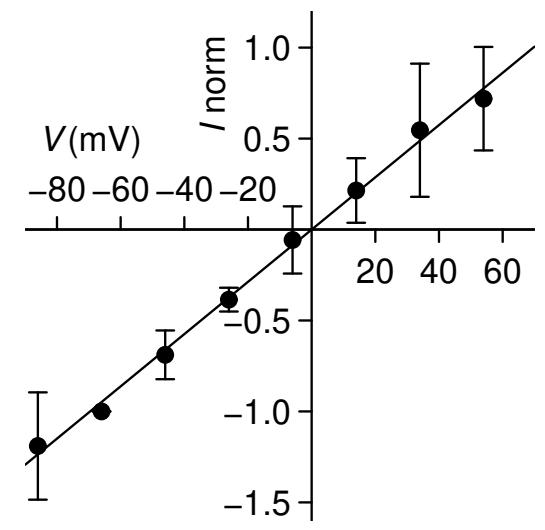

Figure 3: Climbing fibres inputs activate AMPA and NMDA-type glutamate receptors. a. The AMPA/kainate-receptor-mediated component of the climbing fibre EPSC was isolated under control conditions (in the presence of $\mathrm{Mg}$, which blocks NMDA receptors: $c t r l, M g$ ). The NMDAreceptor-mediated component was isolated by application of $4 \mu \mathrm{M}$ NBQX, $45 \mu \mathrm{M}$ D-serine and nominal removal of $\mathrm{Mg}$ ions (NBQX, $0 \mathrm{Mg}$, D-serine). No response was detectable after addition of $50 \mu \mathrm{M}$ APV $(N B Q X, A P V)$. Averages of 21 sweeps. b. The sensitivity of the control response (black) to GYKI 53655 (grey; $50 \mu \mathrm{M}$ ) indicates that no kainate receptors contribute to the non-NMDA-receptor component. Averages of 41 traces. c. Specimen traces showing the voltage dependence of the climbing fibre-interneurone response (using a Cs/TEA-based internal solution and recorded in the presence of bicuculline but the absence of muscimol). Traces were recorded at $20 \mathrm{mV}$ intervals between $-86 \mathrm{mV}$ and $+54 \mathrm{mV}$. Averages of 15 sweeps. d. Pooled I-V data ( $n=3-7$ cells per point) for the EPSC peak normalised to the response at $-66 \mathrm{mV}$, reflecting the AMPA-receptor mediated component. The average voltage dependence is linear with a reversal potential at zero. 


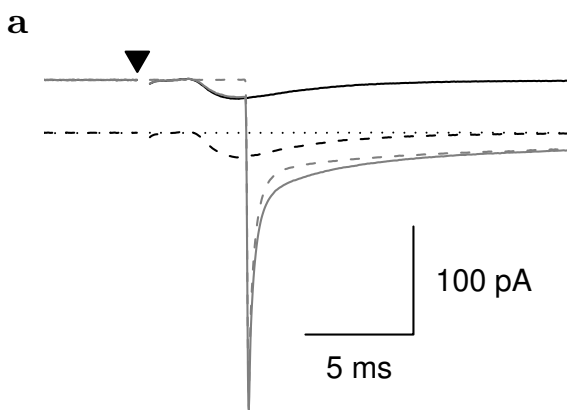

b

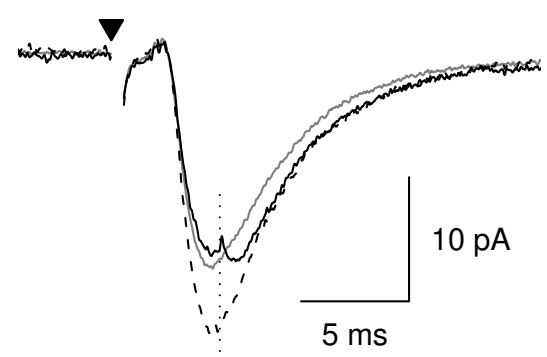

c

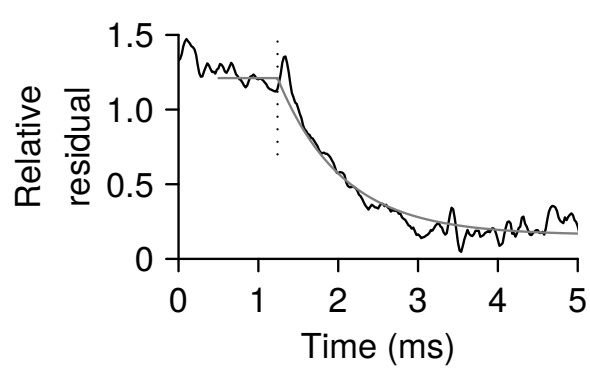

Figure 4: Voltage jumps during the climbing fibre EPSC suggest a dendritic location. a. Current responses to the sequence of voltage jumps and synaptic stimulations required to test for the presence of an active synaptic conductance during the recorded EPSC timecourse. Solid black, EPSC at -68,mV; dotted black, background current at $-98 \mathrm{mV}$; dashed black: EPSC at $-98 \mathrm{mV}$; dashed grey, jump from $-68 \mathrm{mV}$ to $-98 \mathrm{mV}$ in the absence of an EPSC; solid grey, jump shortly after the peak of the EPSC. Averages of $\sim 50$ sweeps. b. The synaptic responses in panel a were separated from the capacity transients by subtraction, yielding the EPSC at $-68 \mathrm{mV}$ (solid grey), the EPSC at $-98 \mathrm{mV}$ (dashed black), and the test EPSC (solid black) subjected to a voltage jump (timing shown by dotted black line). When subjected to a voltage jump, the EPSC rapidly approached that recorded at $-98 \mathrm{mV}$, showing that the synaptic conductance was still active. c. Plot of (EPSC $(-98 \mathrm{mV})$-test EPSC)/(EPSC $(-98 \mathrm{mV})$-EPSC($68 \mathrm{mV})$ ) ('relative residual'; black). This indicates how quickly the test EPSC approached the EPSC at $-98 \mathrm{mV}$. An exponential fit (grey) yielded a time constant of $0.81 \mathrm{~ms}$. The offsets from 1 (before the jump) and 0 (at the end of the decay) probably represent errors caused by random variations in the averages, which are expected to be of a comparable magnitude. 
a

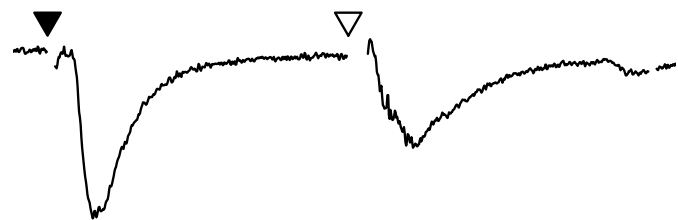

b

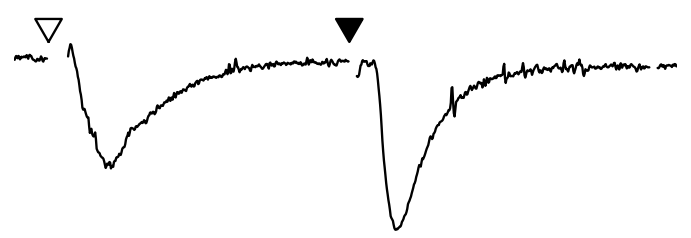

C

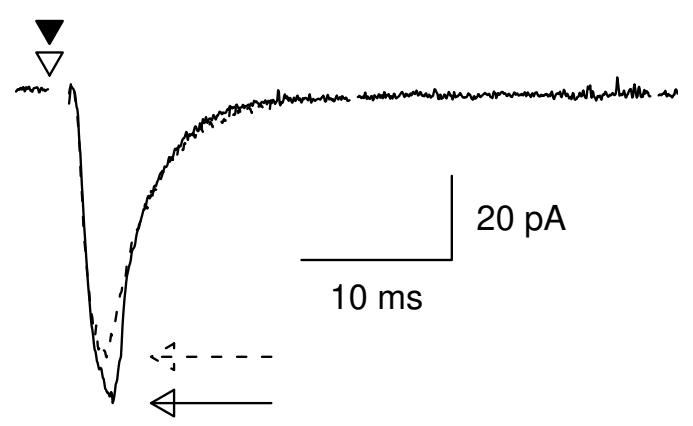

Figure 5: Interneurones are innervated by multiple independent climbing fibres. a. Average responses $(n=9)$ of two putative climbing fibre inputs stimulated in succession. Both displayed paired pulse depression (not shown). The filled and open triangles indicate the stimulus times for the two different stimulation electrodes. b. The same two inputs were stimulated in reverse order. Note that each response has the same amplitude as in panel a, indicating an absence of cross paired-pulse depression. Strong depression would have been expected if the same fibre were being stimulated twice (once by each stimulating electrode). c. When stimulated simultaneously, the compound response (solid line and arrow) was clearly larger than either individual response, proving the existence of two separate inputs. The compound response was slightly larger than the predicted sum of the individual responses (dashed line and arrow), but this difference was not significant on average (see text). 


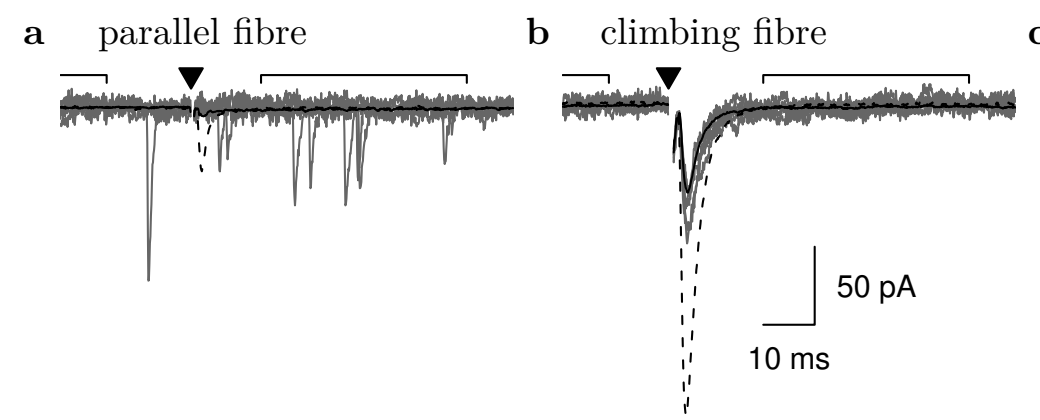

c climbing fibre $+\mathrm{CTZ}$

d

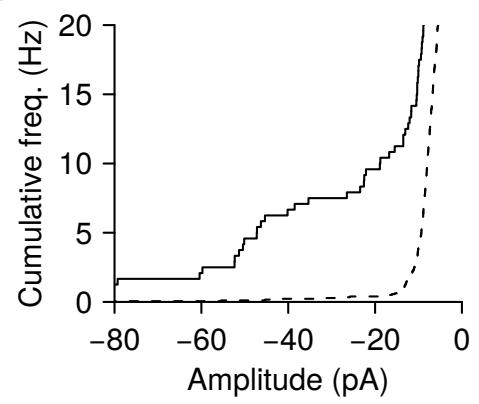

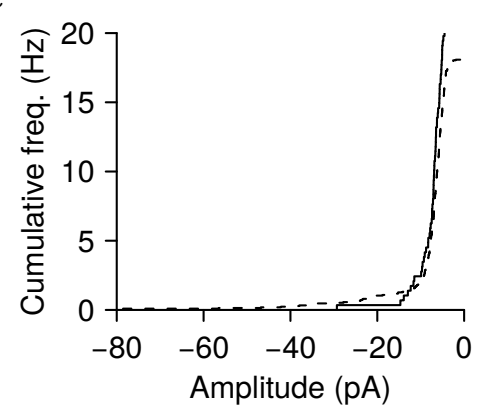

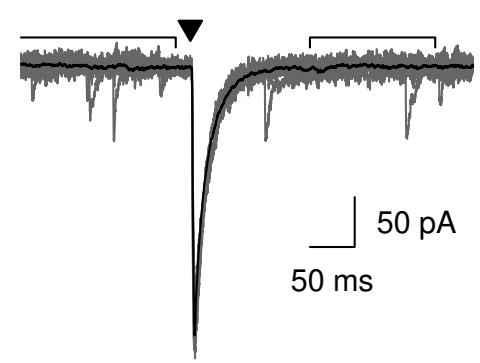

f

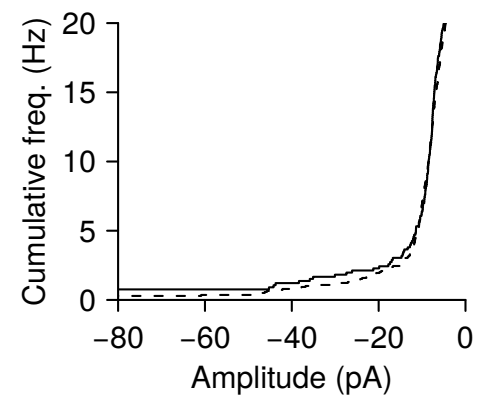

Figure 6: Miniature EPSCs of the climbing fibre could not be detected. a. Average responses of a parallel fibre input in control conditions (dashed black, $n=100$ ) and in $5 \mathrm{mM} \mathrm{Sr}$ with nominally-zero extracellular Ca (solid black, $n=100$ ). Typical specimen sweeps in $5 \mathrm{mM} \mathrm{Sr} / 0 \mathrm{Ca}$ (grey) demonstrate the presence of asynchronous mEPSCs. The horizontal brackets above the traces delimit the end of the pre-stimulus control period (left) and the post-stimulus period (right), during which spontaneous EPSCs and evoked asynchronous mEPSCs were detected, respectively. b. Same experiment as in panel a, but involving a climbing fibre input (the averages are of 30 and 90 traces, respectively). Note the apparent absence of evoked asynchronous mEPSCs in $5 \mathrm{mM} \mathrm{Sr} / 0 \mathrm{Ca}$ (grey specimen sweeps). c. Similar experiment to b but in the presence of cyclothiazide $(100 \mu \mathrm{M})$. Average response is black and individual traces grey. d. Cumulative frequency distribution of EPSCs detected above a threshold of $5 \mathrm{pA}$ before (dashed) and following parallel fibre stimulation (solid). The upstroke around $10 \mathrm{pA}$ reflects the detection level at which noise begins to trigger significant numbers of false positives. A clear excess of EPSCs greater than $10 \mathrm{pA}\left(\mathrm{P}=10^{-11}\right)$, reflecting evoked asynchronous mEPSCs, is apparent following the stimulus. e. Cumulative frequency plot as in panel c, but for the climbing fibre input of panel $b$. There was no significant difference $(\mathrm{P}=0.51)$ in EPSC detection before and after the stimulus. f. Cumulative frequency plot for the climbing fibre/cyclothiazide experiment of panel c; the rate of EPSC detection was not significantly different before and after stimulation $(P=0.72)$ 


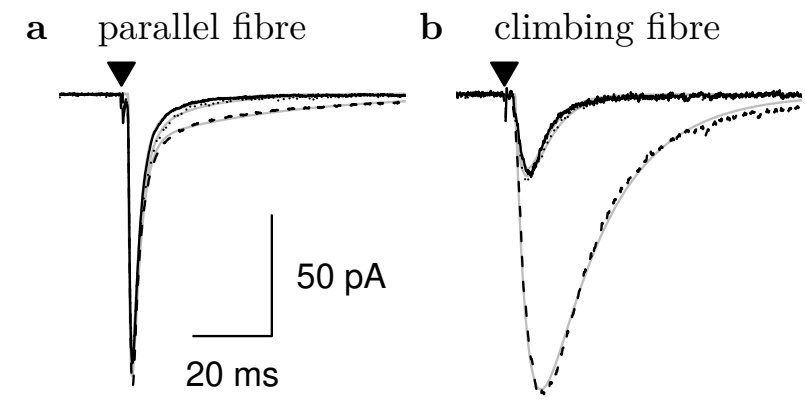

Figure 7: Blocking glutamate uptake potentiates the climbing fibre input. a. The glutamate uptake blocker TBOA $(50 \mu \mathrm{M})$ has little effect on a parallel fibre input, mostly unmasking a small slow component. Control (solid), TBOA (dashed), recovery (dotted). Exponential fits (see text) are shown in grey. Averages of 70, 80, and 19 sweeps, respectively. b. TBOA has a strong effect on a climbing fibre response, potentiating and prolonging the entire EPSC. Same key as in panel a. Averages of 20, 30, and 21 sweeps, respectively.

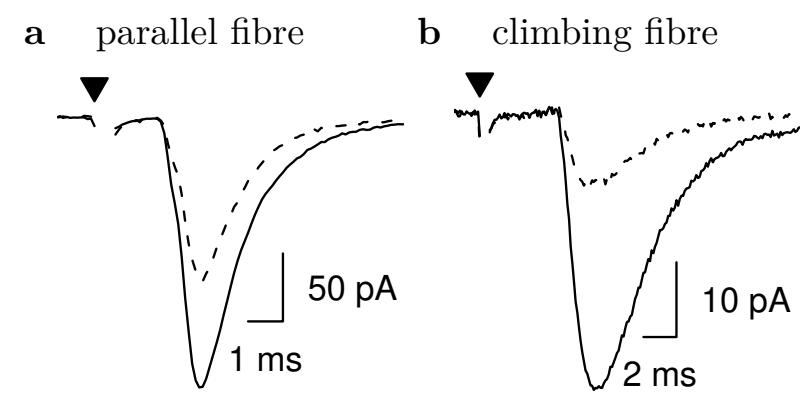

Figure 8: The climbing fibre input is highly sensitive to block by low-affinity AMPA receptor antagonists. a. Average parallel fibre responses $(n=30)$ in the absence (solid) and presence (dashed) of DGG $(0.375 \mathrm{mM})$ b. Average climbing fibre responses $(n=30)$ in the absence (solid) and presence (dashed) of DGG $(0.375 \mathrm{mM})$. The climbing fibre response is blocked by the DGG to a greater degree than the parallel fibre input. 